\title{
Identity, the Main Term of Contrast between “Globalization” and “Universalization”-An Interpretention with a Critical Linguistic Approach
}

\author{
Mohammad Tohidfam, Maryam Khosravi Baraghani, Shahab Dalili \\ Islamic Azad University
}

\begin{abstract}
Communicational and international developments have different aspects in today's world so that some terms like “Internationalization,” “Liberalization,” “Universalization,” “Westernization,” “Deterritorialization” find interferences in social sciences and humanities studies. But these terms can generally be distinguished by two different categories of study as some experts have emphasized that the above developments are in the process (Globalization) while the others considered them on the project (To Globalize). The main problem is that how we can find out the focal point of both studies through which the accuracy of these claims to be verified to know whether contemporary changes and evolutions are formed in a process or a project. It seems that the focal point in the sphere of both claims (processes and projects) is the issue of "identity" since both spheres agree that the concept of "identity" has passed a series of changes and developments, although each one renders the path and goal of "identity" changes by its own specific interpretations. In this article, we claim that using linguistic approach we are able to review the developments and evolutions' flow of identity in the present era and thereby it can be found that the developments in information and communication would lead to creating a process in the context of Globalization or a project on Universalization. The assumption of this study is that by explanation of the above-mentioned situation, we can see that based on the linguistic approach, the process of making identity is “context-based” and "conditional” as opposed to a project view formation and relative continuity of identification process would generally be subject to the condition.
\end{abstract}

Keywords: identity, globalization, universalization, linguistics, proximity, conditionality and contextualism

\section{Introduction}

While some thinkers like Giddens (1991), Wallerstein (1999), Bhawuk (2002), Sklair (1994-1999), and others consider expanding communication and access to information as a modern phenomenon, Robertson (1992), Waters (1995), and Held (1999) believe that the history of this situation goes back to pre-modernity era.

In this regard, it can be traced that various definitions and conflicting views have been insisted on massive

Mohammad Tohidfam, Ph.D., associate professor, Department of Political Science, Islamic Azad University, Tehran Central Branch, Iran; main research field: Political Philosophy. Email: tohidfam_m@yahoo.com.

Maryam khosravi Baraghani, M.A., member of the Academic Board, Department of English, Islamic Azad University, Tehran Central Branch, Iran; main research field: TEFEL (Teaching English as a Foreign Language). Email: m_khosravi_b@yahoo.co.uk.

Shahab Dalili, Ph.D. student, Department of Political Science, Islamic Azad University, Iran; main research field: Political Philosophy. Email: shahabdalili@yahoo.com. 
expansion of communication along with the broad and rapid access to information.

We can refer to definitions like "Internationalization," "Liberalization" (Nash 2010, 10), "Universalization,” "Westernization,” and "Deterritorialization” (Smith 2005, 47-48; Scholte 2005, 6-8).

However in a comprehensive look, all the theories and cited discussions indicate that today's situation has been derived from the advent of "Global Communication Industry" which is defined as a synchronized communicational process and the emergence of a single communicational space which is specified with three characters of being "transnational," "comprehensive," and "continuous" so that it is defined as a process for constantly making a new social space which shows practically that the cultural connections among people in the remotest parts of the world are growing.

Here, the debate and discussion is about the role and purpose of this situation as on one side we have proponents of a change in the name of globalization with its process feature and on the other side those who believe in a program called universalization having the project specification.

This situation has created conflicting interpretations like Janus status with one face forward, one face back, on one hand the unconscious tool of history to stump crushing any shortsightedness and brutality and on the other hand unrelenting assault of greedy capital to the culture realm to provide more benefit at the cost of destroying all human impacts.

Thus, the central question of this article is that how we can find a focal common point in studies of both approaches that clearly explain and evaluate these two approaches and finally reveal that which one is closer to reality.

Today, communication and information have had influences on all spheres of human activity such as society, knowledge, peace... which led to changing the way people think and percept about social relations (Rosenau 1995, 197) and due to this, a wide space for social relations of actors is provided so that by Communication Revolution, interaction of different identities would be appeared in higher quantity and quality. These changes have had a significant impact on thinking and behavior of modern man's "Identity." In fact, "Identity" is a common zone having the ability to reveal how each of these approaches would be associated with reality.

On the other hand, these two approaches essentially explain the above-mentioned situations by approaches like "World Systems," "Global Culture,” "International Community,” "Global Capitalism,” etc. Linguistics in front of this view has emerged claiming that fetching and representing the common point of both approaches of identity study to understand the relations of both approaches toward linguistic approach is possible.

Here, we are going to apply the linguistics approach by which it could be possible to take a look at the problem of "identity" in the era of Communication and Quick Information. The study is followed to find the ratio between the idea of "Universalization project" and "the process of Globalization" to the reality. Hence, at first it is needed to take a theoretical glance at the areas these are overlapped.

\section{Spatial-Temporal Proximity}

Whether we believe the idea of the process of globalization or the universalization project, it is necessary to accept the massive information transfer along with the acceleration in communication networks both in real and virtual worlds. We are receiving news of integrating the Electronic Communication System (Castells 2009, 383) and all products by national and local characters are manufacturing in a transnational space (Tomlinson 1999, $56)$. 
According to Kate Nash (Nash 2010, 71), this situation involves the flow of goods, capital, people, information, and thoughts across borders associated with the emergence of social networks. Barry Oxford (Axford 1995, 34) defines this process as a situation arising from the development of satellites, computers, and kinds of media.

However, regardless of the specifications stated, some thinkers interpret this situation mainly as an economic phenomenon and some groups (Hirst \& Thampson 1996, 176; Touraine 2007, 21) criticize this view and the others consider it as a cultural issue. It is clear that many scholars have works devoted to this subject and so many theories have raised from it. Here we have classified these theories into five main challenges (often sociological polemics).

\begin{tabular}{|c|c|c|c|}
\hline $\begin{array}{l}\text { Five Main } \\
\text { Challenges }\end{array}$ & Claim & & Source \\
\hline \multirow{2}{*}{$\begin{array}{l}\text { Periodic } \\
\text { Challenge }\end{array}$} & Modern & $\begin{array}{l}\text { Expanding communication and accelerating data transfer are } \\
\text { components of Modernism. }\end{array}$ & (Kassel 1383, 424) \\
\hline & Postmodern & $\begin{array}{l}\text { Expanding communication and accelerating data transfer are } \\
\text { linked to Postmodernism. }\end{array}$ & --- \\
\hline \multirow{2}{*}{$\begin{array}{l}\text { Natural } \\
\text { Challenge }\end{array}$} & Economic & $\begin{array}{l}\text { Considered by Economic Nature or to be more balanced by } \\
\text { Capitalism Ideology. }\end{array}$ & \multirow{2}{*}{$\begin{array}{l}\text { (Ohmae 1995, 5) } \\
\text { (Touraine 2007, 21) } \\
\text { (Hirst 1996, 176) } \\
\text { (Waters 1995, 9) } \\
\text { (Waters 2001, 21) }\end{array}$} \\
\hline & Cultural & $\begin{array}{l}\text { Right and left views try to offer radical economic explanations } \\
\text { while these developments have a cultural identity. }\end{array}$ & \\
\hline \multirow{2}{*}{$\begin{array}{l}\text { Acting } \\
\text { Challenge }\end{array}$} & Project & $\begin{array}{l}\text { Insist on activism and intentionality in the development of } \\
\text { communication and information transfer. }\end{array}$ & -- \\
\hline & Process & $\begin{array}{l}\text { Broad communication and data transfer as an emerging } \\
\text { opportunity, a new phenomenon. } \\
\text { Realists insist on the importance of the Nation-State while }\end{array}$ & --- \\
\hline \multirow{2}{*}{$\begin{array}{l}\text { Level } \\
\text { Challenge }\end{array}$} & National & $\begin{array}{l}\text { Historical structural thinkers emphasize on the serious } \\
\text { conseduences in southern countries. }\end{array}$ & \multirow{2}{*}{$\begin{array}{l}\text { (Habermas 1384, 117) } \\
\text { (Roseanu 1995, 346) }\end{array}$} \\
\hline & $\begin{array}{l}\text { Subnational/ } \\
\text { Transnational }\end{array}$ & $\begin{array}{l}\text { Liberals insists on reducing control of National Governments. } \\
\text { They are also mentioned to subnational and transnational actors. }\end{array}$ & \\
\hline \multirow{2}{*}{$\begin{array}{l}\text { Output } \\
\text { Challenge }\end{array}$} & Generalism & $\begin{array}{l}\text { Emerging Generalism along with transformation of particularism } \\
\text { resulted in creating global ethics, values, and culture. }\end{array}$ & $\begin{array}{l}\text { (Tamilson 1386, 153) } \\
\text { (Habermas 1384, 117) }\end{array}$ \\
\hline & Particularism & $\begin{array}{l}\text { Poststructuralists' idea states that this situation has led to the } \\
\text { expansion of particularism and raising sub-cultures. }\end{array}$ & (Robertson 1992, 69) \\
\hline
\end{tabular}

The purpose of expressing these differentiations is trying to release from dogmatic answer to the question that wants to seek which kinds of ideas and approaches (project or process) in describing the developments of communication and information is closer to reality however the question at the end would appropriately be responded.

But what is obvious and both approaches agree on is the matter of shifting and transferring meanings and symbols so as this situation is based on the exchanges between culture and symbols and "symbols" at the current time are considered as a mediator of relations. Above all, since symbols often show human principles and beliefs, they have a global value. We can consider globalization as an aspect of changing cultural characters of social life increasingly (Waters 2002, 186; Tomlinson 1999, 45) as thousands of the smallest everyday actions link millions of people to the fate of unknown persons lived in far-off lands and even to the possible fate of the planet Earth.

"Identity" here is a focal point for the "exchange of meaning" in the present era. Identity as a prerequisite for any social life is a concept related to the realm of meanings but this "Mean" is not necessarily an intrinsic characteristic of the individual and society rather it is a product derived from agreements and disagreements (Jenkins 1996, 5). Therefore, identity is generally a communication concept created in the field of 
undetermined, changeable, and unclear discourses with the warp and woof made of different "elements," "moments," "excellence points," "power relations," and "real systems.” The fact is that identity is considered more as a meaning which makes process rather than a conscious mental process within everyday life can be built. Hence, "identity" is formed in the social processes and synchronized with the relevant evolutions of them. Thus, based on the above considerations, only two things are useful for this article: First is that the major impact on cultural-identical developments is related to the informational-communicational developments and second point refers to the fact that informational-communicational developments in the present age are mainly considered as an evolution occurring in the society and social relations.

\section{Sign, Language, and Meaning}

Accordingly, now the question is: "What is meaning?" "Semiotics as a knowledge of forms evaluates the implications despite their contents" (Barrett 2013, 33) to examine that how "meaning" is created during the process of relationship-building. According to that, "Semiotics" is defined and restricted as "the way of using signs to make the relationship among the people and transfer meaning” (Aslyn 1962, 10). In fact, meaning will be transferred within these relation-making based on the signs.

In this way, Semiotics is not the knowledge on the world, but it is man's knowledge on the world which surveys relationships not objects. The main pre-assumption is that structures have meanings and the function of Semiotics is to analyze the totality of meanings and various forms related to.

Linguistics and Semiotics have different conflicting views as always there have been debates and discussions on the general and specific ratio between "Semiotics" and "Linguistics." However, as was expressed in this article, we do not intend to investigate the theories related to this field of study and linguistics has only been applied as a way to explain (approach).

Of course, here we study language as a general human phenomenon (Chapman 2000, 18) and on the basis of that, linguistics methodologically is a basis which announces that the world is made by relations not objects and epistemological components such as: "Linguistics has a non-causal structure," "Language is subject to the Syntactic and morphological rules," "Language is a social and objective realm," "Meaning only create in the context of the relations of this system," "Belief in the conventional sense," "Belief in the cultural nature of knowledge," "Meaning is not raised from the private experience but it's from some common signifier systems."

In this approach, all human actions find form and meaning in the social space, and this meaning-making more or less builds the reality of the world (Onuf 1989, 22). Making identity is due to the participation in the collective senses (Wendt 1999, 451). Therefore, it’s wrong to consider a fixed value for a specific identity and adhere to it.

\begin{tabular}{|c|c|c|c|c|}
\hline \multicolumn{5}{|c|}{ Main Factors of Linguistic Approach } \\
\hline $\mathrm{n}$ & Factor & Focal Point & Study View & Source \\
\hline 1 & Functionalism & $\begin{array}{l}\text { Making concepts in the structure of } \\
\text { sentences }\end{array}$ & $\begin{array}{l}\text { Evaluating elements of sentence } \\
\text { functionally }\end{array}$ & $\begin{array}{l}\text { (Prnce 1998, 291) } \\
\text { (Givan 1984, 899) }\end{array}$ \\
\hline 2 & $\begin{array}{l}\text { Context of } \\
\text { Situation }\end{array}$ & $\begin{array}{l}\text { Semantics \& Phonology } \\
\text { Describing the meaning based on } \\
\text { the context of position }\end{array}$ & $\begin{array}{l}\text { Analysing relations in the lingual text } \\
\text { Determining relations in the context of } \\
\text { situation }\end{array}$ & ( \\
\hline 3 & Speech Act & $\begin{array}{l}\text { Language is not only means of } \\
\text { information. } \\
\text { Verifying many words couldn't be } \\
\text { determined. }\end{array}$ & $\begin{array}{l}\text { Spokesman by speech act makes non-verbal } \\
\text { act. }\end{array}$ & (Austin 1962, 14) \\
\hline
\end{tabular}


In this way, we can consider "language” as a "social action" (Fairclough 1989, 17), "texts" as a "social products," "spokesmen” as the "people with specific social status," and "meaning” as "products of social relation” (Kress 1990, 85). To sum up, "language” and "sense” and identity are not clear and fixed concepts but these are essentially vague and undetermined.

\section{Conclusion: Linguistic Description of Identity in Contrasting Ideas of Universalization and Globalization}

As stated, linguistics contains two approaches: First approach sees language as a means to show Thinking System which reflects the social processes and second approach emphasizes on the role of shaping social behavior. Anyway what both approaches have focused on is that "language" is not a transparent media that shows us fixed and pre-determined facts.

Accepting the matter of "structured sense," requires that we observe language as a meaning for linking signs which is prior to the individual as an individual creator not individual product.

Hence, the total area of community is in fact a network of different processes in which meaning is produced and nothing in itself has a specific identity but everything gets their sense and identity from the processes of social relations so that "expansion of information and rapid communication transfer" are the biggest factors shaping the field of social relations.

The social meaning of words, terms, actions, and institutions are all understood and interpreted in a general context and each one is a part of this context. Every meaning is only understandable within a series of events so that no political-economic institution or structure by itself undertakes the successful implementation of this century's evolution project.

In this situation, "identity" is not considered as a constant, permanent, and predetermined phenomenon. Identities are created under the processes of social relations. Thus, they are context bound and are defined by the situations they are linked to.

Similar to the linguistic signs, identities will be created in distinction to the "other," so these are communicational and comparative concepts and may never be fixed. This is how the meaning of a sign is never fixed in a process of social relations and there is always a possibility of other meanings to apply.

As a result, "Connectivity" as the starting point of "Cognition" path, in the current era and as a process by which human and social relations occur, maintains and transforms.

This situation has strongly increased cultural exchanges in the world and becomes the agent of global correlation. Through this communication and information, humans in general and citizens in particular have become a "we" in certain respects and have created a bigger identity facing some problems and opportunities. Of course, this does not mean that there is an increasing tendency to make a common and integrated global culture and not only cloning has not occurred in the form of Globalization project but also the present situation is formed by extending communication, rapid transfer of information and being constantly in touch with each other because the world has become a network of social relations, a flow of people and goods in the different zones, a network that conveys the meanings. Hence, this aspect of evolutions has basically a socio-cultural nature.

It can be said that the formation of identity in the present era is fixed. It means that route and process are based on the context and conditionality in which prevalence has a greater value than antiquity and solidity. 
The identity of citizens presented in this situation has an essential relation to information transfer, cultural connectivity, and interacting identities. In this regard, we can clearly observe the development of satellites, the spread of computers, and the increase of media. Therefore, the strength gained by the factors existing in the global relation network along with the mutual interdependences and growing global interconnections increases the scope and impact of how individuals and communities are influenced.

Consequently, identity becomes an important issue which refers to the various kinds of relatively constant and often flexible cognitions defined based on the specific self-attitude and expectations of the others. Hence, identities and interests are relative issues which are defined when we define the situation. Each identity appears through the socio description of actors.

Let us have a quick review focusing on these descriptions. In both cases of project and process of expanding communication and data transfer, the idea of connection in the sense of increasing locational-global proximity is frequently accepted.

The two concepts of "proximity" and "connectivity" theoretically differ from each other in the sense that proximity is a phenomenological sense while connectivity is a visual and noumenal concept. Proximity is intuitive while connectivity is empirical. In fact, connectivity is based on the "presence" but proximity is related to the "appearance." Proximity is a common cognitive concept of the world. Our identity today is a representation and the result of proxmiating various phenomena in the age of communication and data transfer.

It seems that the proximity of identities in the light of developing communication and information transfer has less relevance with the idea of universalization project and is closer to the process of globalization.

The proximity of identities goes beyond an identity contrast; it is an identity clash in a way that the particularization of universalism means the spread of global idea and determination of the human world while Universalization of particularism means the wide dissemination of the idea that there is no limitation to particularism, unity, distinction, and otherness.

As a result, contrary to the idea of the universalization project proponents, identity and its relevant process is always a communicational concept that is formed in the route of socialization and Globalization has helped it as the main factor in this process.

The process of globalization by building a new socio-communicational sphere is the main reason for cultural exchanges among the people of the world in the frame of "a process of growing and interacting connectivity" which is based on the interactions of "culture," "meaning," and "symbol."

Therefore, although the globalization view claims that the informational-communicational changes are basically subjective and intentional and are guided and controlled by the political-economical structure in the interest of multinational corporations and political actors (the powerful countries of the world), by focusing on the way identity has changed in recent years ( which is emphasized in the studies of both globalization process and universalization project) and by implementing the linguistic approach, one can realize that the reasons and interpretations of the Globalization process is more in line with the reality of today's life.

Transferring the meaning and consequently the identity and related changes in this era have occurred in the context of socio-cultural "Connectivity" and "Proximity" processes. So they are not related to subjectivity and intentionality, but they are different and varied due to "Conditionality" and "Contextuality." 


\section{Works Cited}

Austin, John. How to Do Things with Words. Oxford: Oxford University Press, 1962.

Axford, Barrie. The Global System: Economics, Politics and Culture. New York: Palgrave Macmillan Press, 1995.

Barthes, Roland. Mythologies. Publisher Farrar, Straus and Giroux, 2013.

Bhawuk, Dharm. “Globalization and Indigenous Cultures: Homogenization or Differentiation?” International Journal of Intercultural Relations 32 (2008): 305-17.

Castells, Manuel. The Rise of the Network Society. Oxford: Wiley-Blackwell Press, 2009.

Chapman, Siobhan. Philosophy for Linguists: An Introduction. London: Routledge, 2000.

Esslin, Martin. The Field of Drama: How the Signs of Drama Create Meaning on Stage and Screen. The University of California: Publisher Methuen, 1987.

Fairclough, Norman. Discourse and Social Change. London: Wiley Press, 1989.

Giddens, Anthony. Modernity and Self-identity: Self and Society in the Late. San Francisco, Stanford University Press, 1991.

Held, David. Global Transformation. London and New York: The Open University Rutledge Press, 1999.

Hirst, Paul and Thompson Grahame. Globalization in Question: The International Economy and Possibilities of Governance. Cambridge: Polity Press, 1996.

Jenkins, Richard. Social Identity. London: Routledge Press, 1996.

Kress, Gunther. “Critical Discourse Analysis.” Annual Review of Applied Linguistics 17 (1990).

Nash, Kate. Contemporary Political Sociology: Globalization, Politics, and Power. Chichester; Malden: Wiley Blackwell, 2010.

Ohmae, Kenichi. The End of the Nation State: The Rise and Fall of the Regional Economics. London: Harper Collins, 1995.

Onuf, Nicholas Greenwood. World of Our Making: Rules and Rule in Theory and International Relations. Columbia: University of South Carolina Press, 1989.

Robertson, Roland. Globalization: Social Theory and Global Culture. London: Sage Publication, 1992.

Rosenau, James. “Security in a Turbulent World.” Current History 94.592 (1995): 193-200.

Scholte, Jan Aart. Globalization: A Critical Introduction. New York: Palgrave Macmillan Press, 2005.

Selden, Raman and Peter Widdowson. A Reader's Guide to Contemporary Literary Theory. London: Pearson Longman, 1993.

Sklair, Leslie. Capitalism and Development in Global Perspective. London: Routledge, 1994.

---. “Competing Conception of Globalization.” Journal of World System Research 2 (1999): 143-63.

Smith Steve. The Globalization of World Politics: An Introduction to International Relations. Oxford: Oxford University Press, 2005.

Tomlinson, John. Globalization and Culture. Chicago: University of Chicago Press, 1999.

Touraine, Alain. A New Paradigm for Understanding Today World. Cambridge: Polity Press, 2007.

Wallerstein, Immanuel. The Capitalist World Economy. Cambridge: Cambridge University Press, 1979.

Waters, Malcolm. Globalization. London: Routledge, 2002.

Wendt, Alexander. Social Theory of International Politics. Cambridge: Cambridge University Press, 1995.

---. Social Theory of International Politics. Cambridge: Cambridge University Press, 1999. 